\title{
5-7 Year Old Children's Conceptions of Behaving Artifacts and the Influence of Constructing Their Behavior on the Development of Theory of Mind (ToM) and Theory of Artificial Mind (ToAM)
}

\author{
Karen Spektor-Precel \\ Tel-Aviv University and \\ The Open University of Israel \\ Tel-Aviv, Israel
}

karenpr@openu.ac.il

\author{
David Mioduser \\ Tel-Aviv University, \\ Tel-Aviv, Israel
}

miodu@post.tau.ac.il

\begin{abstract}
Nowadays, we are surrounded by artifacts that are capable of adaptive behavior, such as electric pots, boiler timers, automatic doors, and robots. The literature concerning human beings' conceptions of "traditional" artifacts is vast, however, little is known about our conceptions of behaving artifacts, nor of the influence of the interaction with such artifacts on cognitive development, especially among children. Since these artifacts are provided with an artificial "mind," it is of interest to assess whether and how children develop a Theory of Artificial Mind (ToAM) which is distinct from their Theory of Mind (ToM). The study examined a new theoretical scheme named ToAM (Theory of Artificial Mind) by means of qualitative and quantitative methodology among twenty four 5-7 year old children from central Israel. It also examined the effects of interacting with behaving artifacts (constructing versus observing the robot's behavior) using the "RoboGan" interface on children's development of ToAM and their ToM and looked for conceptions that evolve among children while interacting with behaving artifacts which are indicative of the acquisition of ToAM. In the quantitative analysis it was found that the interaction with behaving artifacts, whether as observers or constructors and for both age groups, brought into awareness children's ToM as well as influenced their ability to understand that robots can behave independently and based on external and environmental conditions. In the qualitative analysis it was found that participating in the intervention influenced the children's ToAM for both constructors

Material published as part of this publication, either on-line or in print, is copyrighted by the Informing Science Institute. Permission to make digital or paper copy of part or all of these works for personal or classroom use is granted without fee provided that the copies are not made or distributed for profit or commercial advantage AND that copies 1) bear this notice in full and 2) give the full citation on the first page. It is permissible to abstract these works so long as credit is given. To copy in all other cases or to republish or to post on a server or to redistribute to lists requires specific permission and payment and for the younger observer. Engaging in building the robot's behavior influenced the children's ability to explain several of the robots' behaviors, their understanding of the robot's scriptbased behavior and rule-based behavior and the children's metacognitive development. The theoretical and practical importance of the study is discussed.
\end{abstract} of a fee. Contact Publisher@InformingScience.org to request redistribution permission.

Editor: Janice Whatley

An earlier, shorter version of this paper was presented at the Chais conference 2015, in Raanana, Israel, and included in Y. Eshet-Alkalai, I. Blau, A. Caspi, N. Geri, Y. Kalman, \& V. Silber-Varod (Eds.), Proceedings of the 10th Chais Conference for the Study of Innovation and Learning Technologies 2015: Learning in the Technological Era. Raanana: The Open University of Israel. 
Keywords: Theory of Mind (ToM), Theory of Artificial Mind (ToAM), Cognitive Development, Behaving artifacts, Robots.

\section{Introduction}

In the last decades a new kind of artifact has penetrated our world. We are increasingly surrounded by artifacts that are capable of adaptive behavior, such as electric pots, boiler timers, automatic doors and robots. As a consequent, the traditional and intuitive distinction between the alive and not-alive, animate and inanimate, human-operated and autonomous has become blurred.

Although this new area of the artificial world, the human-mind-made world, is part of our everyday environment, little is known about the genesis and development of the technological stance required to perform within this environment. Thus, the study addressed a domain that up to now has been minimally researched - children's Theory of Artificial Mind (ToAM). The paper focus on children's ToAM, a new theoretical construct, and its characteristics, resemblance to, and differences from children's Theory of Mind (ToM). In general, Theory of mind refers to the ability to understand that others have beliefs, desires, and intentions that are different from one's own, (Davidson, 1984; Dennett, 1987). We examined whether constructing the artificial minds of behaving artifacts influences the development of children's ToAM and their ToM. We focused on children between the ages of 5 and 7 since significant development of cognitive, affective and social systems has been found to emerge between these ages (Sammeroff \& Haith, 1996).

Three main questions were addressed in the current study:

(1) Is ToAM a theoretical scheme distinct from ToM?

(2) What are the effects of interacting with behaving artifacts on children's development of ToAM and ToM?

(3) Which conceptions that evolve among 5- and 7-year-old children while interacting with behaving artifacts are indicative of the acquisition of ToAM?

\section{Structure of the Paper}

We will first present the literature in the area of humans' conceptions of human and behaving artifacts, Theory of Mind, and the use or robotic kits in education. We will then present the gaps in the literature that stem from the literature review. Following, we will present the methodology and results followed by a discussion of the results. Finally, we present the importance and Significance of the Current study, its' limitations and Future Research.

\section{Background}

The literature concerning human beings' conceptions of "traditional" artifacts is vast; however, little is known about our conceptions of behaving artifacts or of the influence of the interaction with such artifacts on cognitive development, especially among children. Since these artifacts are provided with an artificial "mind," it is of interest to assess whether and how children develop a Theory of Artificial Mind (ToAM) which is distinct from their Theory of Mind (ToM). As already mentioned, Theoy of Mind (ToM) refers to the ability to conceive mental states, knowing that other people know, want, feel, or believe things which are different from our own (Premack $\&$ Woodruff, 1978). Most of the studies that focused on the pre-school child examined ToM by means of first-order (such as the False belief task) (Wimmer \& Perner, 1983) and second-order tasks (i.e., understanding what another person thinks a third person knows - the "ice-cream" and the "birthday puppy" stories) (Perner \& Wimmer, 1985; Sullivan, Zaitchik \& Tager-Flusberg, 1994). In the current study, we examined whether "building" an artificial mind enhances the development of the above concepts and causes children to adopt the intentional stance and treat a 
robot as if it had beliefs and desires and as if it acted rationally on these beliefs and desires (Dennett, 1978, 1987).

Much research has been conducted regarding children's conceptions of natural kinds and human made artifacts (e.g., Bloom, 1996; Matan \& Carey, 2001; Ross, Gelman \& Rosengren, 2005). In contrast, research on children's conceptions of behaving artifacts and artificial mind is sparse.

The use of robot construction kits (RCK) in education (such as the LEGO/Logo system) were found to simulate learning concepts and methods in scientific fields such as mathematics, physics, computer science, and mechanics: children learned ideas such as control, feedback, communication principles, and principles of acceleration, deceleration and kinematics (Resnick, 1998; 2006; Resnick, Berg, \& Eisenberg, 2000; Resnick, Martin, Sargent \& Silverman, 1996; Resnick \& Ocko, 1991), decentralized systems, emergent phenomena and aspects of engineering, design, artistic expression, programming and scientific inquiry (Druin, 2000), scientific research skills (Datteri, Zecca, Laudisa \& Castiglioni, 2012), cognitive and academic skills such as deductive reasoning, reading comprehension and geometrical problem-solving (Caci, D'amico, \& Chiazzese, 2012), literacy and numeracy skills as well as interpersonal skills (McDonald \& Howell, 2012), sequencing ability (Kazakoff, Sullivan, \& Bers, 2013), and computational, programming and robotics abilities (Bers, Flannery, Kazakoff, \& Sullivan, 2014).

Studies by the group of Mioduser and his colleagues examined various aspects of children's conceptions of behaving artifacts: Levy and Mioduser (2008) examined which frameworks are used by 5- to 6-year-old children when reasoning about a robot. Mioduser and Levy (2010) examined young children's ability to construct and explain adaptive behaviors of a robot. Mioduser and Kuperman (2012) found that in 5- to 6-year-old's explanations of programmable adaptive artifacts as a function of the complexity the level of involvement in constructing the robot's behavior affected children's explanations

\section{Gaps in the Literature}

The theoretical review indicates that knowledge is constructed throughout interaction with robots that serve as "objects to think with" (Papert, 1980) as well as that interacting with technological devices, including robots, has an influence on children's cognitive development. To the best of our knowledge, no studies have examined children's ToAM or its development as a consequence of the construction of the robots' behaviors. In the current study we would like to enlarge the body of research existing in this area and examine the nature and essence of the differences between 5- and 7-year-old children in their conceptions, ToM and ToAM characteristics and their development following interaction with adaptive robots including constructing their behavior.

\section{Methodology}

\section{Research Design}

A mixed methods approach (Johnson \& Onwuegbuzie, 2004) combined with a microgenetic approach (Siegler \& Chen, 1998) was used in the current study.

\section{Research Population}

Participants were 24 children: (a) twelve 5-year-old children, 8 boys and 4 girls, attending public kindergartens in central Israel (socioeconomic status defined as mid-high), whose ages spanned 4 years 10 months to 6 years, with a mean age of 5 years 6 months and a standard deviation of 4.5 months, and (b) twelve 7-year-old children, 5 boys and 7 girls, attending public elementary schools in central Israel (socioeconomic status defined as mid-high) whose ages spanned 6 years 1 month to 7 years 3 months, with a mean age of 6 years 6 months and a standard deviation of 5 
months (see Table 1). The battery of tests and tasks was administered to all the children. The children's parents signed consent forms approving their child's participation in the study. Following the parents' approval, children were selected and divided randomly for the mode of interaction (observation and construction). The conduct of the study was approved by the chief scientist of the Israeli Ministry of Education.

Table 1: The research population

\begin{tabular}{|l|l|l|l|}
\hline Age group & Age range & $\begin{array}{l}\text { Mean } \\
\text { (years, } \\
\text { months) }\end{array}$ & $\begin{array}{l}\text { Stdv } \\
\text { (in months) }\end{array}$ \\
\hline $\begin{array}{l}\text { 5-year-olds } \\
\text { N=12 } \\
\text { (Male=8; Female=4) }\end{array}$ & 4y10m-6y & $5 y 6 \mathrm{~m}$ & $4.5 \mathrm{~m}$ \\
\hline $\begin{array}{l}\text { 7-year-olds } \\
\text { N=12 } \\
\text { (Male=5; Female=7) }\end{array}$ & 6y1m-7y3m & $6 y 6 \mathrm{~m}$ & $5 \mathrm{~m}$ \\
\hline
\end{tabular}

\section{The research population for the qualitative analysis}

Two 5-year-olds (a boy aged 5 years and 3 months and a girl aged 4 years 11 months and 22 days at the beginning of the study) and two 7-year-olds (two boys aged 6 years and 4 months at the beginning of the study) from the total research population were randomly chosen for the qualitative analysis. In each age group there was one constructor and one observer.

\section{Research Instruments}

Two main research instruments were used in the proposed study: (1) A robotic environment, and (2) Data collection tools.

\section{The "RoboGan" computerized interface}

A robotic learning environment which was developed for young children, the "RoboGan" (Mioduser, Levy, \& Talis, 2009) was used in the study. This environment includes a computer interface (Figure 1), a physical robot (made with the LEGO ${ }^{\circledR}$ system) and modifiable "landscapes" for the robot's navigation (Figure 2). The environment is an iconic interface for defining the control rules in a simple and intuitive fashion (Mioduser et al., 2009, Talis, Levy, \& Mioduser, 1998). The right panel in Figure 1 presents the progression of the modes of constructing the robot's behavior, moving through level of difficulty from remote control behavior (top, easy task) to two interrelated rules (bottom, advanced task). The central section is devoted to the "Desktop" in which children construct behavior procedures, which change according to the stages. In each of the right panel's modes, the options for carrying out the assignment are related to the task so that the construction of the behavior of the robot is intuitive. The learning of the options is accomplished while performing the tasks. For example, in Figure 1 (high complexity task), children construct a rule for the robot's behavior. The construction of the behavior rule requires reference to two input modes (light, darkness). The child is required to drag icons that represent the expected behavior in conditions of light and darkness, thus constructing a rule for the robot's behavior. Upon constructing the rule, it is downloaded to the robot using the "download" icon (circled). 


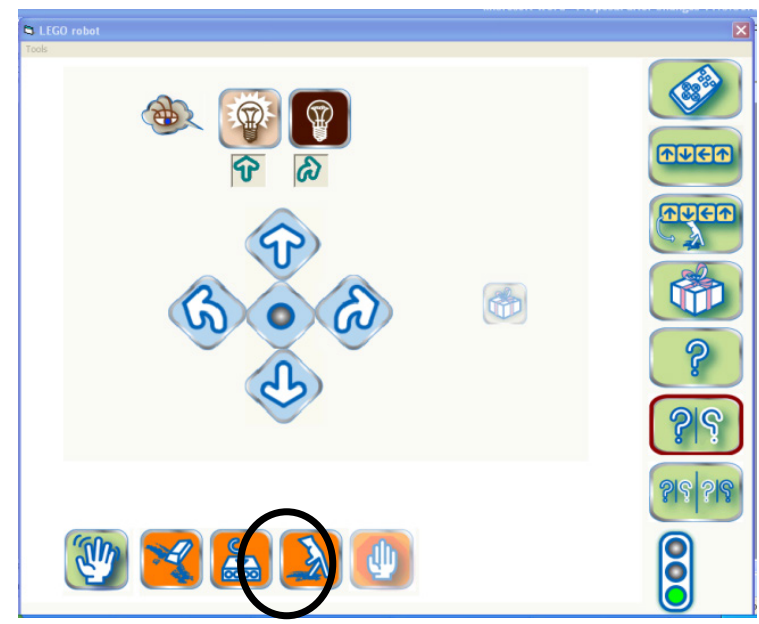

Figure 1. The computer interface

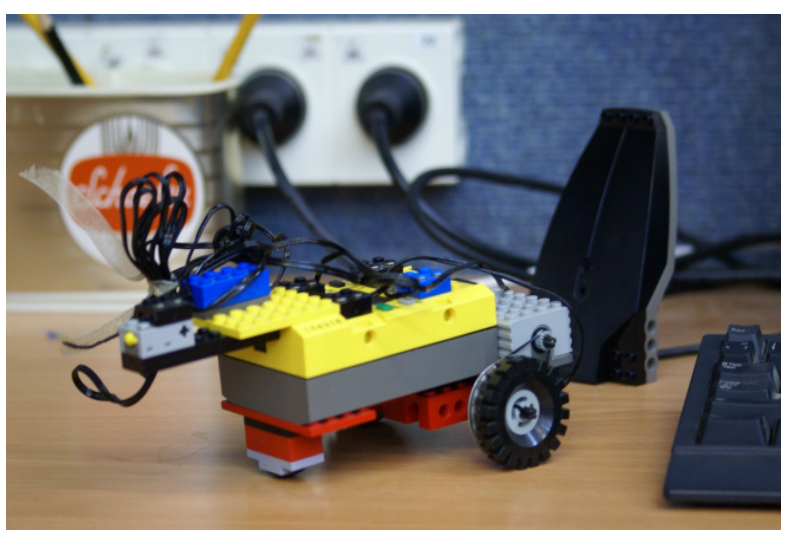

Figure 2. The robot made of LEGO

\section{Data collection tools}

Three sets of data collection tools were used in the study: (1) intelligence (IQ) test, (2) Pre-Post tests and (3) Process tasks.

\section{Intelligence (IQ) test}

The Hebrew version (Peyser, Shimborsky, Wolf, \& Hazany, 1996) of the Kaufman Assessment Battery for Children (K-ABC) (Kaufman \& Kaufman, 1983) was used in order to characterize the research population as homogeneous in relation to intelligence. This battery is a standardized test that assesses intelligence and achievement in children aged 2.5 to 12.5 years. This tool was chosen because both age groups in the proposed study are within the age range for which this battery is designed. The test consists of 18 subtests - 10 mental processing subtests and 8 achievement subtests. Out of the 18 subtests, children were administered three subtests: (1) riddles (achievement scale), (2) matrix analogies (simultaneous processing scale), and (3) word order (sequential processing scale). These subtests were chosen because (1) they all appear in the English short version, (2) each belongs to one of the three possible categories (appearing in parentheses), (3) they are suitable for administration to subjects in both age groups, and (4) these tasks have high split-task inner reliability.

\section{Pre- and Post-tests}

Children were administered pre- and post-tests that relate to the 2 dependent variables: assessment of ToM and assessment of ToAM. 
(A) Assessment of the development of ToM: Two main types of tasks were used:

(1) Tasks that assess classic aspects of ToM (understanding of first and second order beliefs). For example, in a first order Diverse desires task the child is presented with a doll and two pictures: of a carrot and a cookie.
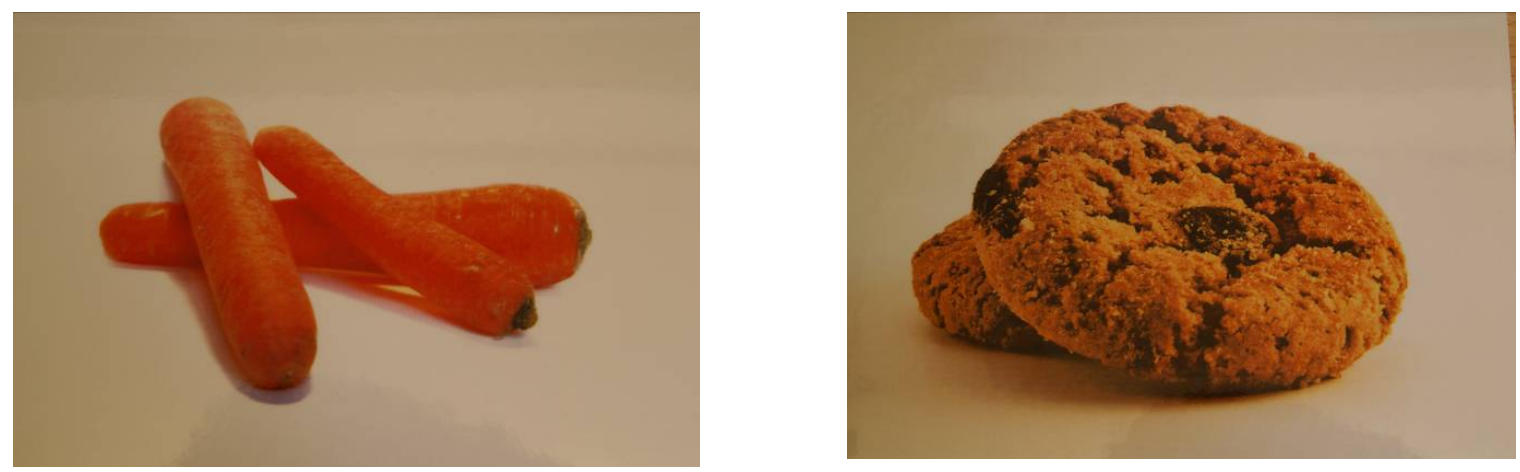

The child is told, "Here's Dana. It is 10:00am break time and it's time to eat a snack. Dana wants to eat. She has two snacks she can choose from."

The child is asked the "desire" question, "Which snack do you like best: a cookie or a carrot?" If the child chooses the cookie (carrot) he is told: "This is an excellent choice. But in fact, Dana likes carrots (cookies). She does not like cookies (carrots)."

The child is asked the target question, "So it is time to eat. Dana can choose only one snack. Which snack will Dana choose? A cookie? A carrot?"

In addition, the child is asked to give an explanation for his answer. To perform this task correctly the child must answer that Dana will choose the snack that he did not chose and his explanation should refer to Dana's desires.

(2) New tasks that assess aspects of the human mind that relate to behavior control and adaptivity and were not part of previous ToM studies.

For example, in the Diverse desires decision making task, the child is presented with a doll and two pictures: of an ice-cream and a cookie.
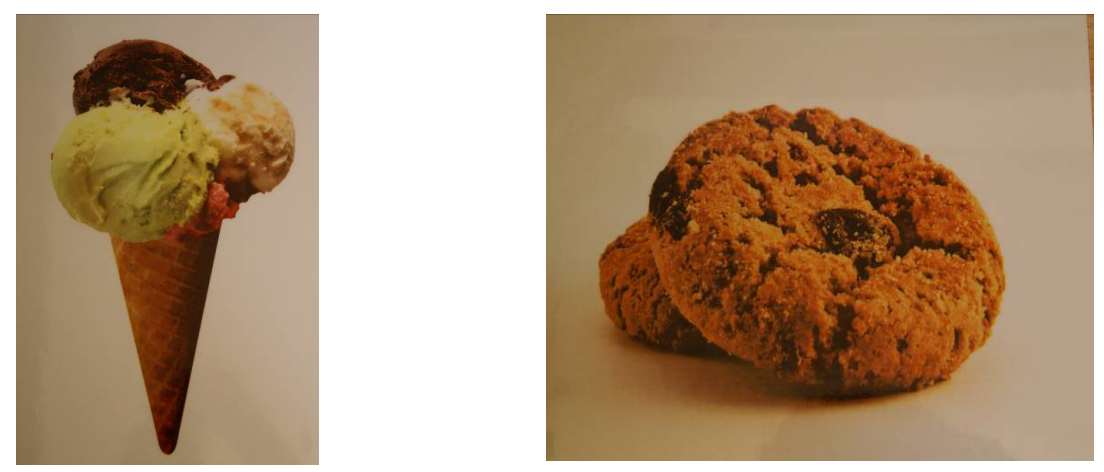

The child is told, "Here's Tom. Tom eats ice-cream during the day and a cookie at night. It's time for dessert. Eyal can eat only one dessert." The child is then asked the target question, "Which dessert will Eyal choose? - ice-cream or cookie?"

In addition, the child is asked to give an explanation for his answer. 
To perform this task correctly the child must answer that Eyal will choose his dessert based on the time of day.

(B) Assessment of the development of ToAM: Two main batteries of tasks were used:

(1) Adaptation of the classic ToM tasks to assess ToAM:

For example, in the "No will" task, the child is presented with a doll and a robot.

The child is told the following, "Roey has a robot. The robot can move forward or backwards. Roey operated the robot to move forward. When he put the robot on the floor the robot moved backwards." Then, the child is asked the "no will" question, "What do you think happened?" or "Can this happen? If so - why? and if not - why not?". In addition, the child is asked to give an explanation for his answer.

To perform this task correctly the child must present an answer that indicates to us that he understands that the robot's behavior is dependent on its programming and that the robot does not have a will, such as "Roey didn't operate the robot well" or "The robot was programmed to go backwards."

(2) Tasks that were developed for the study in order to assess aspects of the artificial mind that relate to behavior control and adaptivity:

For example, in the "No will - decision making task", the child is presented with a robot and a container filled with red and blue balloons.

The child is told, "When a child celebrates his or her birthday during the day RED balloons are used. When the birthday celebration is at night BLUE balloons are used. There is a pile of balloons in the container. The robot is located next to the container." The child is asked the target question, "Which balloon will the robot pull out?" In addition, the child is asked to give an explanation for his answer.

To perform this task correctly, the child must say that if the robot was programmed to make a decision it will first check the light outside (using light

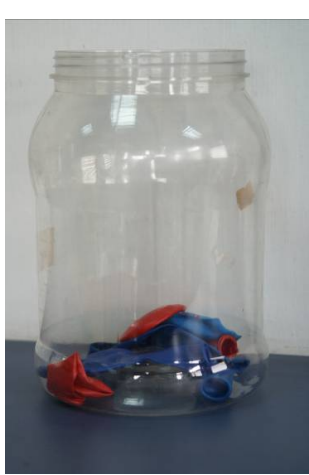
sensors) and thus will be able to pull out the correct balloons.

Each battery of tasks contained 10 tasks ( 5 ToM and 5 ToAM tasks) in two versions (A and B). The entire battery was administered twice: in the pre-test and post-test sessions of the study in a counterbalanced order.

\section{Process tasks}

In order to assess the influence of constructing the robot's behavior on the development of ToM and ToAM, Nine tasks and three boards were developed and constructed. The tasks were divided into four levels of complexity (1-4; 1 - low level of complexity; 4 - high level of complexity) based on the cognitive demands made on the participants in order for them to accomplish the task:

(1) The script learning tasks require basic thinking. The outcome of the participants' or the experimenter's actions is immediate and no advance planning is needed.

(2) The script programming tasks require temporal and sequential thinking. Advance planning is needed and the outcome of the actions is apparent only after the programming is completed. The children (or experimenter) teach the robot a specific set of fixed actions for performing an expected and finite behavior. For example, we used the "going to the basketball yard" task (see Figure 3), in which the robot is placed in a neighborhood with one school, a play-ground and a basketball yard. 


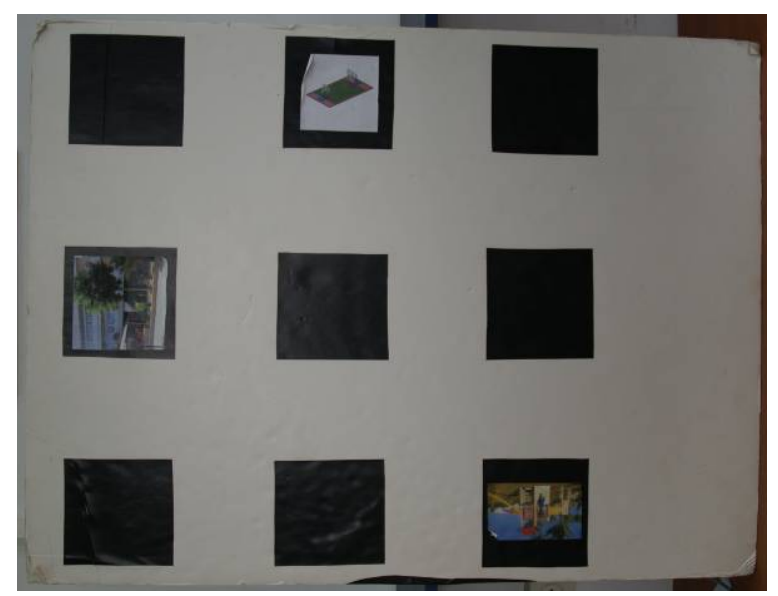

Figure 3. "Going to the basketball yard" board

The children are instructed to program (or observe) the robot to go to the basketball yard.

(3) The half-rule tasks require a-temporal and general associative thinking between environmental conditions and the robot's actions (if-then rules). However, participants referred only to one output for one input (if - output A).

(4) The full-rule tasks also require a-temporal and general associative thinking between environmental conditions and the robot's actions; however participants referred to the two values of the rule - two outputs in correspondence with the two input values of the conditions (if-else output A, output B).

For example, we used the "politeness task" (see Figure 4). In this task the robot is placed upon a white surface with black areas.

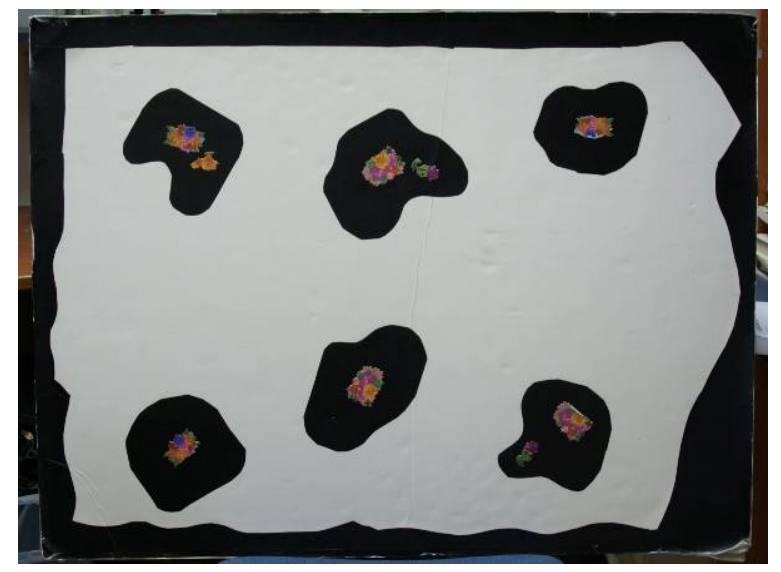

Figure 4. "The politeness task" board

The children are instructed to program (or observe) the robot to move freely on the white surface while being polite - without touching the black areas.

Children in the construction group constructed the robot's behavior according to the task and children in the observation group saw the robot's behavior which had been constructed by the experimenter. Children in the observation group were not exposed to the interface nor did they at any time see the experimenter constructing the robot's behavior. 


\section{Procedure}

Children were administered the Kaufman Assessment Battery for Children (K-ABC) assessing their intelligence, a battery of pre- and post-tests that assess the development of first- and secondorder ToM and ToAM (that were developed for the study), and process tasks administered during the intervention that assess the concepts which are indicative of the acquisition of ToAM. Children were selected and divided randomly into one of two groups: observation or construction of the robot's behavior. Data was collected in nine to ten 20-30-minute sessions. All sessions were recorded and videotaped and later analyzed.

\section{Qualitative Data Collected During the Pre- and Post-Tests and Manipulation Process}

Based on the data collected during the pre- and post-tests and observations, criteria were constructed by two independent judges. Reliability was assessed on one fourth of the data and was based on an agreement of $89.78 \%$ between the judges.

\section{Data Analyses}

Three types of analysis were conducted in the current study:

(1) The Kaufman Intelligence test: Two-way ANOVA was conducted to examine differences between groups on performance.

(2) Analysis of the raw data of all tasks that were collected in the theory of mind and theory of artificial mind pre- and post-tests. This analysis includes the mean accuracy of children's answers in each task separately, followed by the analysis of children's explanations.

(3) Analyses as a function of the research questions: this analysis included analysis of the mean of the correct responses and of the frequency of children's explanations in all tasks in order to answer research question 2 and Qualitative analysis - in order to answer the third research question. In the latter we analyzed four case studies. Within the construction and observation groups, we looked for concepts that evolve during the intervention that support the acquisition of ToAM, looking for age differences in the concepts that evolve and looking for the influence of the type of involvement on the concepts that evolve.

Analyses \#2 and \#3 served in order to answer research question 1.

\section{Results and Discussion}

The purpose of the current study was to examine the existence of a new scheme named ToAM and to examine the effects of constructing the robots' behavior on children's development of ToM and ToAM. We focused on children between the ages 5 and 7 since significant development of cognitive, affective, and social systems were found to emerge between these ages.

The main results of the current study can be summarized as follows:

Intelligence was not found to be a confounding variable in the current study.

\section{Analysis of the Raw Data}

In the ToM analysis by task we found that, in general, the intervention influenced children's understanding of first-order decision making based on beliefs and desires which are dependent on environmental conditions. In the second-order tasks we found two levels of basic second-order 
understanding while only one level of decision making second-order understanding. Lastly, we found that for all children it was easier to grasp decision making than beliefs and desires.

In the ToAM analysis by task we found that only in the second-order tasks, but not in the firstorder tasks, the intervention may have influenced constructors more than observers. In the second-order tasks we assume one level of second-order understanding.

We found that even though ToM and ToAM share several characteristics (both include first-order and second-order understanding, rule-based understanding, and decision making and adaptive behavior understanding) most of their characteristics differ in the following ways: (1) in their essence, (2) in the content of first- and second-order understanding, and (3) in children's ability to grasp several of the ToM or ToAM concepts.

\section{The essence of ToM and ToAM}

While ToM first-order understanding consists of understanding that another individual holds beliefs and desires which are different than our own and that another person can make decisions based on desires and beliefs that are different than our own, ToAM first-order understanding consists of understanding that the robot has no will, rather, its operation depends on either direct operation or programming, that robots behave according to environmental conditions and make decisions accordingly (rule understanding), and that robots behave according to either direct operation or human programming that are dependent on environmental conditions.

\section{The content of first- and second-order understanding}

While ToM second-order understanding ( $\mathrm{SOU}$ ) consists of understanding what character ' $\mathrm{A}$ ' thinks character ' $\mathrm{B}$ ' knows, and understanding that character ' $\mathrm{A}$ ' thinks that character ' $\mathrm{B}$ ' makes decisions based on environmental conditions and behaves accordingly, ToAM second-order understanding refers to understanding a scenario in which robots ' $A$ ' and ' $B$ ' operate according to a program and that the operation of robot ' $B$ 's depends on the output of robot ' $A$ ', and understanding what robot ' $B$ ' would do following a change in the behavior of robot ' $A$ ', both of which are dependent on programming.

\section{Children's ability to grasp several of the ToM or ToAM concepts}

While in ToM understanding of rules includes only complex rules, ToAM includes understanding of half and full rules. In addition, ToAM, but not ToM, includes understanding of scripts. We also found that hypothetical decision making in robots (i.e., "can the robot help finding a dog?") is harder for children to grasp in contrast to concrete behavior of a robot (i.e., "which balls/balloons will the robot pull?") and with decision making in humans that is based on beliefs (i.e., "Where would Ronen look for the dog?"). These findings supports the dichotomy between abstractconcrete concepts (e.g., Altarriba, Bauer, \& Benvenuto, 1999; Paivio, Yuille, \& Madigan, 1968). Thus, it might be that ToM and ToAM are two separable schemes that develop independently.

\section{Analysis of the Research Questions}

In order to answer the first research question, Is ToAM a theoretical scheme distinct from ToM?, we will first present the main results of questions 2 and 3.

\section{Research question 2}

Research question 2: What are the effects of interacting with behaving artifacts on children's development of ToM and ToAM? 
ANOVA (repeated measures) was calculated for 2 (pre-post) X 2 (age) X 2 (condition) to examine differences within the pre- and post-tests and between the age and condition groups for all tasks.

Concerning ToM, we found that, in general, the interaction with behaving artifacts, whether as observers or constructors and for both 5- and 7-year-old children, brought into awareness children's ability to understand that other people hold different beliefs and desires than their own, and that the human mind's ability to make decisions is based on beliefs and desires which are dependent on environmental conditions $[\mathrm{F}(1,20)=5.992, \mathrm{p}<.05]$.

Concerning ToAM, we found that, in general, the interaction with behaving artifacts, whether as observers or constructors and for both 5- and 7-year-old children, influenced the children's ability to understand that robots can behave independently and based on external and environmental conditions, as well as the relationship between the behaviors of two robots $[F(1,20)=13.867$, $\mathrm{p}=.001]$.

These findings are in line with previous findings that indicated the construction of knowledge via interaction with robots that serve as "objects to think with" (e.g. Caci et al., 2012; Granott, 1991; 1993; 2002, Papert, 1980).

\section{Research question 3}

Research question 3: Which conceptions that evolve among 5- and 7-year-old children while interacting with behaving artifacts are indicative of the acquisition of ToAM?

The qualitative analysis of the intervention sessions among four children indicated differences and similarities between the 5- and 7-year-old children and between children who constructed and observed the robot's behavior in four major areas: (1) conceptions that evolve among 5- and 7year-old children while interacting with behaving artifacts are indicative of the acquisition of ToAM, (2) immunity to functional fixedness, (3) Meta cognition, and (4) development in children's language in their conceptions of the artificial mind.

\section{Conceptions that evolve among 5- and 7-year-old children while interacting with behaving artifacts are indicative of the acquisition of ToAM}

We found various conceptions that evolve among 5- and 7-year-old children while interacting with behaving artifacts which are indicative of the acquisition of ToAM. For example, we found that the engagement in building the robot's behavior in both 5-year-old and 7-year-old constructors enhanced a full technological model of the mind (i.e., " "The tower is connected to the computer. The computer passes it [the information] to the robot"). We also found that Engaging in building the robot's behavior influenced the children's ability to explain several of the robot's behaviors, their understanding of script-based and rule-based behavior (i.e., "The robot will behave the same... because it received an input from the tower... what I told it... to go backwards in strong light"). These findings too, support Papert's constructionism theory (1980).

\section{Immunity to functional fixedness}

Among the constructors, we found that both 5- and 7- year-old children evidenced immunity to functional fixedness (which refers to a situation when subjects are hindered in reaching a solution to a problem by their knowledge of an object's conventional function (Duncker, 1945), in relation to their conceptions of the artificial mind, while among the observers, only the younger observer showed such flexibility. We assume that engaging in the construction of artifacts contributed to the older child's immunity to cognitive fixedness. It might be that while constructing the robot's behavior and building its mind even older children become epistemologists which can enhance their construction of general knowledge (Papert, 1980, 1986) and the robot's ability to make 
choices based on environmental changes and traits (or decision making), and its ability of adaptive behavior. We suggest that older children who were found to be less flexible in their thinking and learning compared to younger children in previous studies (German \& Defeyter, 2000; Defeyter \& German, 2003), become flexible in their thinking, similar to the younger children, when engaged in an activity that involves programming.

\section{Meta Cognition}

We found evidence for Meta Cognition among both constructors that reflected on their own learning and thinking, even at the early age of 5: "In the second level every time I pressed on a row the robot moved. In the third level it didn't move. It was more difficult for me to do [the third level] because I didn't know what to do. I showed you what I planned to do and it helped me because I already knew what to do... Eventually I succeeded because I thought". We found that only the constructors reached higher-order thinking and were capable of thinking about their own thinking, an indicator of their metacognitive abilities. In other words, engaging in constructing the robot's behavior influenced children's metacognitive abilities. Our findings support previous findings relating to the effect of learning computer and robotic programming on children's metacognitive abilities (Casteldine \& Chalmers, 2011; Clements \& Gullo, 1984; La Paglia, Caci, La Barbera, \& Cardaci, 2010). We indeed believe that "by programming the behavior of a robot, the student has to get inside the mind of the RCK, and think about thinking!' (Lau, Kiat-Tan, Erwin $\&$ Petrovic, 1999, p. 28), and we also assume that the children's ability to reflect on their thinking can provide them with confidence to solve problems in authentic situations (Kramarski, Mevarech \& Arami, 2002), and might contribute to reflecting on their learning in curricular settings as well.

\section{Development in children's language in their conceptions of the artificial mind}

We found that during the intervention children used both technological language and a combination of technological-psychological language. We found evidence of a correlation between the level of difficulty of a task and the language used by the children: as the task became harder, the language became a "bridging" one (see also Levy \& Mioduser, 2008), combining both technological and psychological concepts. We also found that observers tended to use such combining language more than constructors. Based on previous studies (Levy \& Mioduser, 2008; Mioduser \& Kuperman, 2012; Mioduser \& Levy, 2010), we assume that the children's use of such bridginganthropomorphic language was either because it helped the children in solving the more difficult tasks or because it was more convenient or functional for them, and not because they attributed human-like characteristics to the robot.

\section{Research question 1}

Research question 1: Is ToAM a theoretical scheme distinct from ToM?

Results of both qualitative and qualitative analyses indicated the existence of a theoretical scheme -ToAM- in 5- and 7-year-old children.

We found that ToAM is comprised of the following:

First- and second order understanding (in artifacts).

(1) A model of the artificial mind with the following continuum: (a) a ToM-like model completely based on children's model of the human mind; (b) a ToM-based ToAMtechnological model referring to the artificial mind but using elements borrowed from their model of the human mind; (c) a partial ToAM-technological model referring to the existence of the artificial mind (i.e., reference to the input and output of the robot), but not to the content or processing of the artificial mind; (d) a fully technological ToAM model. 
(2) The type of ToAM model children hold. When they evidenced a ToM-based ToAM model (TbTa), a partial ToAM model (PToAM), or a fully technological ToAM model (FT ToAM), we distinguished between two types of models: (1) an "obeying" technological model (OMM - Obeying Model of the Mind) referring to the robot as having an obeying-dependent mind that obeys external sources, and (2) an "adaptive" of the artificial mind (AMM) technological model referring to the robot as having a mind that makes decisions based on environmental conditions.

(3) Understanding of script-based behavior.

(4) Understanding of half-rule and full-rule based behavior.

\section{Importance and Significance of the Current study}

The current study supplied significant insights both theoretically and practically.

Theoretically, the findings broadened the existing knowledge at different levels. In relation to the literature concerning ToM, our study enlarged the existing data in several directions. The current study is the first attempt to refer to children's perception of aspects of the human mind's ability to make decisions within the framework of ToM studies. As a result of expanding the classic ToM tasks to include aspects of decision making, we were able to characterize two levels of ToM decision making: one that refers to beliefs and the second that refers to desires. Finally, our study indicated that interacting with behaving artifacts influences children's conceptions of the human mind.

In relation to the literature concerning ToAM, although we know much about the development of the theory of the human mind, the domain of children's conceptions of the artificial mind is at an early stage. Our findings indicated a new theoretical scheme we defined as ToAM. Our study unveiled the characteristics and components of this new scheme. We also found that interacting with behaving artifacts influenced the development of ToAM. Additional research is needed in order to establish these theoretical ideas in relation to both ToM and ToAM.

In relation to the concepts evolving that support the acquisition of ToAM while interacting with behaving artifacts, the current study supplies important insights at several main levels: (a) the identification of intriguing aspects of children's thinking about behaving and adaptive artifacts, (b) the nature of suitable tools, tasks, and "objects to think with" allowing children to enact, construct, and reflect on their understandings of the world of behaving artifacts, and (c) the language used while interacting with behaving artifacts. Our study also enlarged existing data in relation to the ages of 5-7 years as important in development, young children's immunity to functional fixedness, and the influence of constructing artificial behavior on the development of ToAM and on metacognitive abilities.

Our study also indicated the importance of combining quantitative and qualitative analysis. We have learned from the current study that only by combining quantitative and qualitative research methods were we able to receive a complete and coherent picture of children's ToM, ToAM, the influence of constructing adaptive behavior on these constructs, and the concepts that evolve while interacting with behaving artifacts that support the acquisition of ToAM.

Practically, this theoretical knowledge has clear implications for education, supporting the development and implementation of learning environments in the area of intelligent machines and control already in pre-school. These environments should enable young children to enact and construct artificial behavior by themselves, which will enable them to reflect on their understanding of the world of behaving artifacts and the artificial mind and, as a consequence, on the world of the human mind. This, in turn, will support their acquisition of metacognitive knowledge relating to their engagement in the construction of behaving artifacts including decision-making skills, 
acquisition of programming capabilities, robotics knowledge, construction of artificial behavior and problem-solving skills on the one hand, as well as supporting their acquisition of metacognitive regulation abilities such as self-reflection. These, in turn might contribute to their understanding of the human mind, as well as enabling them to regulate and reflect on their curricular leaning.

\section{Limitations of the Current study}

The current study has several limitations. Participants were 5- and 7-year-old children from kindergarten and primary schools in central Israel, and thus the sample was not representative of the entire population of children in Israel of the target ages. In addition, the children were from high socio-economic backgrounds and might have encountered behaving artifacts previous to their participation in the study. Also, the number of participants was not large and might have influenced some of the non-significant differences obtained in the quantitative analyses of the study. Bearing these limitations in mind, the results and conclusions obtained in the current study can be generalized only to similar populations.

In addition, participants were selected randomly out of each class and were divided randomly to the two conditions (observers and constructors), and thus, the sampling was a non-probability sampling but rather was a convenience sampling.

\section{Future Research}

With respect to the limitations and the preliminary results of the current study, future research should include a larger population size and expand the study to diverse socio-economic backgrounds including more rural populations that might have less exposure to smart machines from an early age.

A large-scale study (in terms of population characteristics, sampling methods, scope of construction tasks and developmental aspects of both ToM and ToAM) will provide robust data on the trends unveiled so far, which will enlarge the body of research in relation to children's conceptions of the artificial mind.

\section{References}

Altarriba, J., Bauer, L. M., \& Benvenuto, C. (1999). Concreteness, context availability, and imageability ratings and word associations for abstract, concrete and emotion words. Behavior Research Methods, Instruments, \& Computers, 31, 578-602.

Bers, M. U., Flannery, L., Kazakoff, E. R., \& Sullivan, A. (2014). Computaional thinking and tinkering: Exploration of an early childhood robotics curriculum. Computers \& Education, 72, 145-157.

Bloom, P. (1996). Intention, history and artifact concepts. Cognition, 60, 1-29.

Caci, B., D'amico, A., \& Chiazzese, G. (2012). Robotics and virtual worlds: An experiential learning lab. Advances in Intelligent Systems and Computing, 196, 83-87.

Castledine, A-R., \& Chalmers, C. (2011). LEGO Robotics: An authentic problem solving tool? Design and Technology Education: An International Journal, 16(3), 19-27.

Clements, D. H., \& Gullo, D. F. (1984). Effects of computer programming on young children's cognition. Journal of Educational Psychology, 76(6), 1051-1058.

Datteri, E., Zecca, L., Laudisa, F., \& Castiglioni, M. (2012). Explaining robotic behaviors: A case study on science education. Proceedings of the $3^{\text {rd }}$ International Workshop Teaching Robotics, Teaching with Robotics Integrated Robotics in School Curriculum. Trento, Italy: Riva del Garda. 
Davidson, D. (1984). Thought and talk. In D. Davidson (Ed.), Inquiries into truth and interpretation (pp. 155-170). Oxford: Oxford Univ. Press.

Defeyter, M. A., \& German, T. P. (2003). Acquiring an understanding of design: Evidence from children's insight problem solving. Cognition, 89, 133-155.

Dennett, D. C. (1978). Brainstorms: Philosophical essays on mind and psychology. Cambridge, MA: MIT Press.

Dennett, D. C. (1987). The intentional stance. Cambridge, MA: MIT Press.

Druin, A. (2000). Robots for kids: Exploring new technologies for learning experiences. San Francisco: Morgan Kaufman / Academic Press.

Duncker, K. (1945). On problem solving. Psychological Monographs, 58, 5 (Whole No. 270).

German, T. P., \& Defeyter, M. A. (2000). Immunity to functional fixedness in young children. Psychonomic Bulletin \& Review, 7(4), 707-712.

Granott, N. (1991). Puzzled minds and weird creatures: Phases in the spontaneous process of knowledge construction. In I. Harel \& S. Papert (Eds.), Constructionism. Norwood, NJ: Ablex.

Granott, N. (1993). Microdevelopment of co-construction of knowledge during problem-solving: Puzzled minds, weird creatures, and wuggles. Doctoral dissertation, Massachusetts Institute of Technology, Cambridge, MA [on line]. Available at http://theses.mit.edu:80/Dienst/UI/2.0/Composite/0018.mit.theses/1993-170/1?nsections=19

Granott, N. (2002). How microdevelopment creates macrodevelopment: Reiterates sequences, backward transitions, and the Zone of Current Development. In: N. Granott \& J. Parziale (Eds.), Microdevelopment: Transition processes in development and learning. Cambridge University Press.

Johnson, R. B., \& Onwuegbuzie, A. J. (2004). Mixed methods research: A research paradigm whose time has come. Educational Researcher, 33(7), 14-26.

Kaufman, A. S., \& Kaufman, N. L. (1983). Kaufman Assessment Battery for Children (K-ABC). Bloomington, MN: Pearson Assessments.

Kazakoff, E. R., Sullivan, A., \& Bers, A. U. (2013). The effect of a classroom-based intensive robotics and programming workshop on sequencing ability in early childhood. Early Childhood Education Journal, $41,245-255$.

Kramarski, B., Mevarech, Z., \& Arami, M. (2002). The effects of metacognitive instruction on solving mathematical authentic tasks. Educational Studies in Mathematics, 49(2), 225-250.

La Paglia, F., Caci, B., La Barbera, D., \& Cardaci, M. (2010). Using robotics construction kits as metacognitive tools: A research in an Italian primary school. In B. K. Wiederhold et al. (Eds.), Annual Review of Cybertherapy and Telemedicine, 210, (pp. 110-114). The interactive media institute and IOS press.

Lau, K. W., Kiat-Tan, H., Erwin, B. T., \& Petrovic, P. (1999). Creative learning in school with LEGO(R) programmable robotics products. Frontiers in Education Conference, 10-13 Nov. 1999. FIE '99. 29th Annual (Volume 2, pp. 12D4/26 - 12D4/31. IEEE.

Levy, S. T., \& Mioduser, D. (2008). Does it "want” or "was it programmed to..."? Kindergarten children's explanations of an autonomous robots" adaptive functioning. International Journal of Technology and Design Education, 18, 337-359.

Matan, A., \& Carey, S. (2001). Developmental changes within the core of artifact concepts. Cognition, 78, $1-26$.

McDonald, S., \& Howell, J. (2012). Watching, creating and achieving: Creative technologies as a conduit for learning in the early years. British Journal of Educational Technology, 43(4), 641-651.

Mioduser, D., \& Kuperman, A. (2012). Kindergarten children's perceptions of "Anthropomorphic Artifacts" with adaptive behavior. Proceedings of the Chais conference on instructional technologies re- 
search 2012: Learning in the Technological era. Y. Eshet-Alkalai, A. Caspi, S. Eden., N. Geri., Y. Yair, Y. Kalma. (Eds.), Raanana: The Open University of Israel.

Mioduser, D., \& Levy, S. T. (2010). Making sense by building sense: Kindergarten children's construction and understanding of adaptive robot behavior. International Journal of Computers in Mathematical learning, 15, 99-127.

Mioduser, D., Levy, S. T., \& Talis, V. (2009). Episodes to scripts to rules: Concrete-abstractions in kindergarten children's explanations of a robot's behavior. International Journal of Technology and Design Education, 19, 15-36.

Paivio, A., Yuille, J. C., \& Madigan, S. A. (1968). Concreteness, imagery, and meaningfulness values for 925 nouns. Journal of Experimental Psychology, 76, 1-25.

Papert, S. (1980). Mindstorms: Children, computers and powerful Ideas. NY: Harvester Press.

Papert, S. (1986). Constructionism: A new opportunity for elementary science education. Proposal to the National Science Foundations. MIT Media Laboratory.

Perner J., \& Wimmer, H. (1985). John thinks that Mary thinks that: Attribution of second order beliefs by 5-year-old to 10-year-old children. Journal of Experimental Child Psychology, 39, 437-71.

Peyser, M., Shimborsky, G., Wolf, N., \& Hazany, I. (1996). Kaufman assessment battery for children: Israeli version. Jerusalem: Ministry of education, culture and sports - psychological and counseling services, the Henrietta Szold institute for research in behavioral sciences.

Premack, D., \& Woodruff, G. (1978). Does the chimpanzee have a 'theory of mind'? Behavioral and Brain Sciences, 4, 515-526.

Resnick, M. (1998). Technologies for lifelong kindergarten. Educational Technology Research \& Development, 46(4), 43-55.

Resnick, M. (2006). Computer as paint brush: Technology, play, and the creative society. In D. Singer, R. Golikoff, \& K. Hirsh-Pasek (Eds.), Play = Learning: How play motivates and enhances children's cognitive and social-emotional growth. Oxford: Oxford University Press.

Resnick, M., Berg, R., \& Eisenberg, M. (2000). Beyond black boxes: Bringing transparency and aesthetics back to scientific investigation. Journal of the Learning Sciences, 9(1), 7-30.

Resnick, M., Martin, F., Sargent, R., \& Silverman, B. (1996) Programmable bricks: Toys to think with. IBM Systems Journal, 35(3-4), 443-452.

Resnick, M., \& Ocko, S. (1991). LEGO-Logo: Learning through and about design. In I. Harel \& S. Papert (Eds.), Constructionism. Norwood: Ablex.

Ross, B. H., Gelman, S. A., \& Rosengren, K. S. (2005). Children's category-based inferences affect classification. British Journal of Developmental Psychology, 23, 1-24.

Sammeroff, A., \& Haith, M. (1996). The five to seven year shift. Chicago, IL: The University of Chicago Press.

Siegler, R. S. \& Chen, Z. (1998). Developmental differences in rule learning: A microgenetic analysis. Cognitive Psychology, 36, 273-310.

Talis, V., Levy, S. T., \& Mioduser, D. (1998). RoboGAN: Interface for programming a robot with rules for young children. Tel-Aviv University.

Sullivan, K., Zaitchik, D., \& Tager-Flusberg, H. (1994). Preschoolers can attribute second-order beliefs. DevelopmentalPsychology, 30, 395-402.

Wimmer, H., \& Perner, J. (1983). Beliefs about beliefs: Representation and constraining function of wrong beliefs in young children's understanding of deception. Cognition, 13, 103-128. 


\section{Biographies}

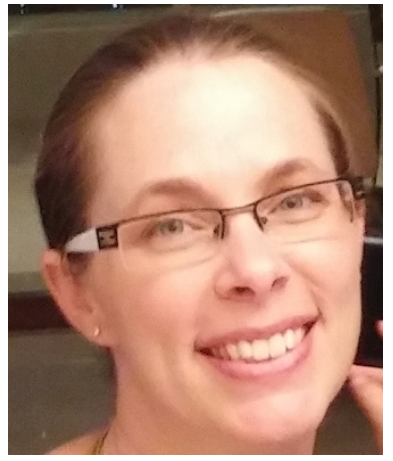

Dr. Karen Spektor-Precel is a Cognitive Psychologist and a researcher at the Science and Technology Education Center (SATEC) at the School of Education at Tel-Aviv University, faculty in the Education and Psychology department at the Open University of Israel, and a researcher at the Chais Research Center for the Integration of Technology in Education. She has published academic papers in journals and national and international conferences in her research work, including Technology in Education focusing on young children's cognitive development and learning aspects in the technological world, Design of computerized Learning Environments, E-learning, Usability and in Cognitive Psychology - ADHD and Learning and Reading Disabilities.

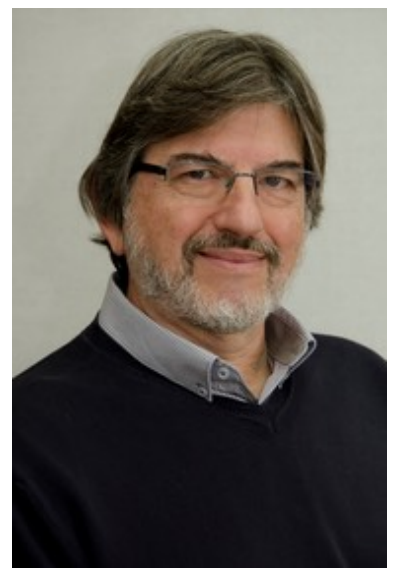

Prof. David Mioduser is the Head of the school of Education at Tel Aviv University. In the past served as head of the Science and Technology Education Center and head of the Department of Mathematics, Sciences and Technology Education in the School of Education. His research work deals with cognitive and learning aspects of ICT in education, the development of technological thinking and reasoning by young children, and Control and Robotic Systems in Education. In recent years he has been a research partner in international studies conducted under the auspices of the European Union, the OECD and the IEA on integrating up-to-date technology in teaching and learning. He acts as member in a number of leading Israeli committees dealing with ICT in education, Technology Education and Information Science. 